\title{
The T-box transcription factor Tbx18 maintains the separation of anterior and posterior somite compartments
}

\author{
Markus Bussen, ${ }^{1}$ Marianne Petry, ${ }^{1}$ Karin Schuster-Gossler, ${ }^{1}$ Michael Leitges, ${ }^{2}$ Achim Gossler, ${ }^{1}$ \\ and Andreas Kispert ${ }^{1,3}$ \\ ${ }^{1}$ Institut für Molekularbiologie, Medizinische Hochschule Hannover, 30625 Hannover, Germany; ${ }^{2}$ Max-Planck-Institut für \\ experimentelle Endokrinologie, 30625 Hannover, Germany
}

The compartmentalization of somites along their anterior-posterior (AP) axis is pivotal to the segmental organization of the vertebrate axial skeleton and the peripheral nervous system. Anterior and posterior somite halves contribute to different vertebral elements. They are also characterized by different proliferation rates and properties with respect to neural crest cell migration and spinal nerve passage. AP-somite polarity is generated in the anterior presomitic mesoderm by Mesp2 and Delta/Notch signaling. Here, we demonstrate that maintenance of AP-somite polarity is mediated by the T-box transcription factor Tbx18. Mice deficient for $T b \times 18$ show expansion of pedicles with transverse processes and proximal ribs, elements derived from the posterior lateral sclerotome. AP-somite polarity is established in Tbx18 mutant embryos but is not maintained. During somite maturation, posterior somite compartments expand most likely because of posterior cells invading the anterior somite half. In the anterior lateral sclerotome, $T b \times 18$ acts as an antiapoptotic factor. Ectopic expression experiments suggest that $T b \times 18$ can promote anterior at the expense of posterior somite compartments. In summary, Tbx18 appears to act downstream of Mesp2 and Delta/Notch signaling to maintain the separation of anterior and posterior somite compartments.

[Keywords: Somite; skeleton; vertebra; Uncx4.1; mesoderm]

Supplemental material is available at http://www.genesdev.org.

Received February 12, 2004; revised version accepted March 29, 2004.

The metameric organization of the vertebral column derives from the somites, segmentally repeated units in the paraxial mesoderm. Somites form by epithelialization of mesenchymal cells at the anterior end of the unsegmented presomitic mesoderm (PSM). On signals from the notochord and the ventral neural tube, the ventral half of the somite deepithelializes and forms the mesenchymal sclerotome. The dorsal somite half remains epithelial, forming the dermomyotome, which will give rise to striated muscles and the dermis of the body. Some of the sclerotomal cells migrate medially and form the perichordal tube, an initially unsegmented mesenchyme that will give rise to the vertebral bodies and the intervertebral discs. In contrast, neural arches and ribs can be traced back to lateral sclerotomal regions (for reviews on somitogenesis and vertebral column development, see Christ et al. 2000; Pourquie 2001; Saga and Takeda 2001; Gossler and Tam 2002).

In addition to dorsoventral patterning, somites are po-

${ }^{3}$ Corresponding author.

E-MAIL kispert.andreas@mh-hannover.de; FAX 49-511-5324283.

Article and publication are at http://www.genesdev.org/cgi/doi/10.1101/ gad.300104. larized along their anterior-posterior (AP) axis, leading to subdivision into an anterior (cranial) and a posterior (caudal) compartment (Keynes and Stern 1984, 1988). On the molecular level, this compartmentalization can already be detected at the anterior end of the unsegmented PSM (Bettenhausen et al. 1995; Saga et al. 1997). A morphological manifestation only becomes evident between somite stages $\mathrm{V}$ and $\mathrm{X}$ when a thin cleft (von Ebner fissure) separating anterior and posterior halves of the lateral sclerotome emerges (von Ebner 1888). Shortly afterward, cell density in posterior compartments appears higher than in the anterior ones (Verbout 1985). Cells of anterior and posterior somite (sclerotome) halves differ not only with respect to proliferation rates, but also with respect to their adhesive properties. Cells of different anterior or posterior halves, respectively, mix on experimental juxtaposition. However, a compartment boundary is maintained when anterior somite halves are placed next to posterior somite halves (Stern and Keynes 1987).

AP-somite polarity imposes a segmental organization on adjacent tissues, particularly the peripheral nervous system. Both neural crest cells and spinal nerves of motoneurons only pass through anterior somite halves, a behavior mediated by repulsive signals from posterior 
somite halves (Keynes and Stern 1984, 1988; Rickmann et al. 1985; Wang and Anderson 1997).

The metameric units of the adult and the embryonic precursor tissue, the vertebrae with the ribs and the somites, respectively, do not directly relate to each other. One vertebra is composed of cells from the posterior half of one somite and the anterior half of the next somite; that is, the intrasomitic border represents the intervertebral boundary. This phenomenon, termed resegmentation, or Neugliederung (Remak 1850) has gained experimental support by cell labeling and transplantation experiments in the chick /Goldstein and Kalcheim 1992; Aoyama and Asamoto 2000; Huang et al. 2000). These works also illuminated that anterior and posterior somite compartments contribute differently to the various parts of the vertebra. Vertebral bodies, laminae with the spinal processes, the rib heads, and the distal ribs derive from both somite halves. Pedicles with their transverse processes and proximal ribs derive from posterior somite halves only. Because resegmentation only concerns sclerotomal derivatives but not the dermomyotome, intervertebral and intercostal muscles link two ribs and two vertebrae, respectively, together.

AP polarization of somites is initiated by interaction of the Delta/Notch signaling pathway with the basic helix-loop-helix (bHLH) transcription factor Mesp2 (for a recent review on the role of Delta/Notch signaling in somitogenesis, see Rida et al. 2004). Mesp2 interacts in two opposing manners with Notch signaling. First, Mesp2 activates a Presenilin-independent Notch signaling pathway, which suppresses Dll1 expression, thus specifying the anterior somite half. Then, a Ps1-dependent Notch signaling cascade induces Dll1 expression in the caudal somite half, leading to specification of the posterior somite compartment (Takahashi et al. 2000, 2003). Loss of Mesp2 leads to expansion of Dll1 expression and posteriorization of somites (Saga et al. 1997). In contrast, absence of Dll1 results in anteriorization of somites (Hrabe de Angelis et al. 1997). Reduction of Mesp2 expression in D111 and Notch1 mutant embryos, but also reduction of Notch1 expression in Mesp2 mutants, argues for a complicated feedback loop of Delta/ Notch and Mesp2 function (Takahashi et al. 2000, 2003).

Little is known about the molecular requirements that mediate maintenance and elaboration of AP-somite polarity. Uncx4.1 und Tbx18 represent a pair of genes whose expression suggests a role in either process. Uncx4.1 encodes a paired-type homeobox transcription factor whose expression is restricted to posterior somite halves (Mansouri et al. 1997; Neidhardt et al. 1997). Initiation of this expression depends on D111, whereas further maintenance requires Uncx4.1 itself (Barrantes del Barco et al. 1999; Mansouri et al. 2000). Mice homozygous for a targeted mutation of the Uncx4.1 gene exhibit severe malformations of the axial skeleton. Pedicles with transverse processes and proximal ribs, elements derived from the posterior lateral sclerotome, are lacking along the entire length of the vertebral column of Uncx $4.1^{-/-}$newborns. AP-somite polarity is established in Uncx4.1 mutant embryos, suggesting that Uncx4.1 indeed is required for maintenance of posterior somite characteristics (Leitges et al. 2000; Mansouri et al. 2000).

Tbx18 encodes a T-box transcription factor with an expression pattern in the developing somite and sclerotome suggestive of a function complementary to that of Uncx4.1 in somite development. Tbx18 is expressed in two stripes in the anterior PSM, representing anterior halves of two newly forming somites, S-1 and S0. In the somitic mesoderm, Tbx18 expression is restricted to anterior somite halves, first in the entire half, and later down-regulated in the dermomyotome but maintained in the lateral sclerotome (Kraus et al. 2001). Thus, Tbx18 may be required for epithelialization or for initiation and/or maintenance of AP-somite polarity. Additionally or alternatively, Tbx18 may play a role in the formation and/or differentiation of the sclerotome.

To address the functional significance of somitic Tbx18 expression in mouse development, we have generated a targeted mutation resulting in a functional null allele of the gene. Mice homozygous for the mutant allele die shortly after birth as a result of severe skeletal malformations. The metameric organization of the vertebral column is partly lost in lateral vertebral regions. Pedicles and proximal ribs form a contiguous band. Histological and molecular analyses suggest that Tbx18 prevents cells from the posterior somite half from invading the anterior compartment. Overexpression of $T b x 18$ in somites leads to reduction of the posterior somite compartment. Posterior lateral sclerotome is reduced, as evidenced by thinning and partial loss of pedicles and proximal ribs. Hence, $T b x 18$ is not only required to maintain anterior somite identity, but it is also sufficient to promote anterior at the expense of posterior somite halves.

\section{Results}

Targeted disruption of the Tbx18 gene

To elucidate the role of Tbx18 in somite development, we used gene targeting in embryonic stem (ES) cells to generate mice deficient for the Tbx18 gene (Fig. 1). The lacZ gene of Escherichia coli preceded by an internal ribosomal entry site (IRES) was inserted into the $5^{\prime}$-untranslated region located in exon 1 to visualize endogenous $T b x 18$ expression from the mutated allele by $\beta$-galactosidase activity staining (Fig. 1A). RFLP analysis and down-regulation of Tbx18 mRNA in homozygous mutant embryos (Fig. 1B,C; Supplemental Material) confirmed that the targeted modification of the Tbx18 locus resulted in a functional null allele.

\section{Postnatal lethality and skeletal malformations in $\mathrm{Tbx} 18^{-/-}$embryos}

Mice heterozygous for the mutant Tbx18 allele appear normal and are fertile. In contrast, no viable homozygotes were recovered from heterozygous intercrosses at 2 wk of age (>200 offspring). However, homozygotes were 
A

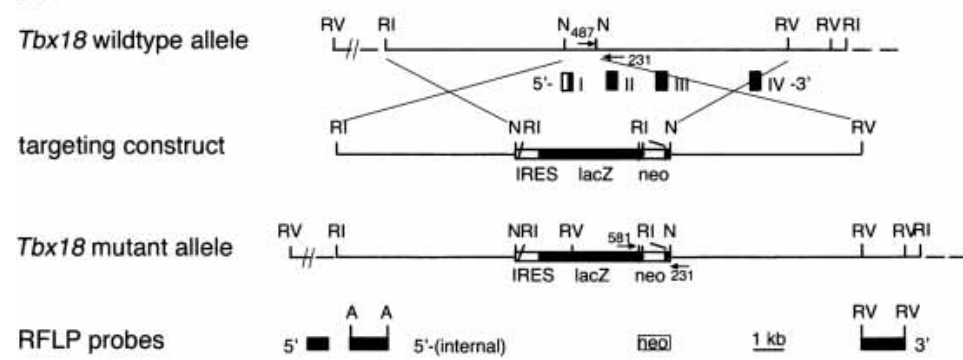

B

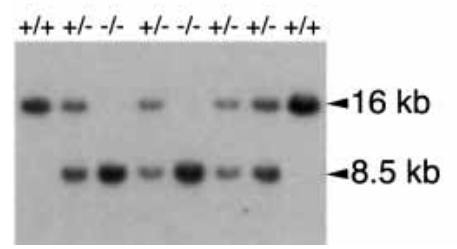

C

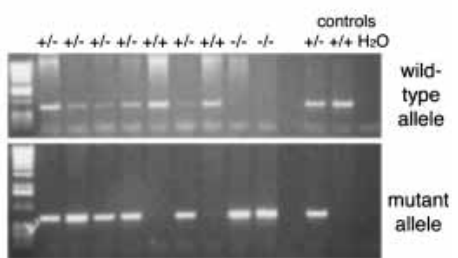

Figure 1. Targeted disruption of the Tbx18 locus. $(A)$ Schematic representation of the targeting strategy. Restriction map of the wild-type locus with boxes representing the first four exons of $T b x 18$; coding regions are shown in black, noncoding in white. Arrows show location and orientation of PCR primers. Fragments used as RFLP probes are shown. The EcoRV fragment designated as $3^{\prime}$ detects the EcoRI-RFLP shown in B. (A) ApaI; (N) NotI; (RI) EcoRI; (RV) EcoRV; (neo) loxPflanked neomycin selection cassette; (IRES) internal ribosomal entry site. $(B)$ Southern blot analysis of EcoRIdigested genomic DNA extracted from E18.5 embryos derived from intercrosses of Tbx18/+ mice. Genotypes are indicated above each lane. The $16-\mathrm{kb}$ and $8.5-\mathrm{kb}$ band represent the wild-type and the mutant allele, respectively. (C) PCR genotyping of embryos from heterozygous matings using primers specific for the wild-type (upper panel) and the mutant allele (lower panel), respectively. The genotypes are indicated above each lane. observed at the expected Mendelian ratio from embryonic days 10-18 (E10 to E18) as well as shortly after birth (data not shown). Mutant pups that are characterized by a shortened body die shortly after birth after having taken few and irregular breaths (Fig. 2B). Histological analysis of newborn $T b \times 18^{-/-}$pups revealed that the external morphology can be attributed to severe malformations of the vertebral column and the thoracic cavity (Fig. 2D). Intervertebral discs are reduced and delocalized, as indicated by irregularly formed nuclei pulposi within them (Fig. 2D,F). Hardly inflated lungs (Fig. 2D) support the notion that perinatal lethality is caused by respiratory failure.

The observed pathological changes are fully penetrant. No gross morphological defects were observed in the cardiovascular system and the limbs on the mixed genetic background used for this analysis. Defects in other organ systems are currently under analysis and will be reported separately. Removal of the PGK.neo cassette from the mutant Tbx18 allele (Tbx18Aneo) did not affect the mutant phenotype.

To evaluate the nature and severity of the vertebral column defects, we made skeletal preparations of Tbx $18^{-/-}$embryos $(n>10)$ and wild-type littermates $(n>10)$ at E18.5 (Fig. 2G-O). The skull and the appendicular skeleton appear grossly normal (Fig. 2G). However, the axial skeleton of the mutant is characterized by multiple defects. The metameric organization of the vertebrae and attached ribs is markedly impaired within the cervical and thoracic sometimes even extending into the lumbar region. Pedicles of neural arches with their transverse processes and the proximal regions of the ribs are expanded to form contiguous bony bands (Fig. 2G,I,M,O). Segmentation of lateral vertebral structures is largely retained within the lower lumbar, sacral, and tail regions of the mutant skeleton. However, pedicles within the lumbar region display a symmetrical rather than the polarized shape seen in the wild type (Fig. 2K). Segmentation is retained along the entire vertebral column in ven- tral vertebral structures (vertebral bodies), the dorsal part (laminae), and in the distal and the most proximal part of the ribs, the rib heads (Fig. 2G,I,K,M,O). Partial or complete fusion of the occipital bone and the atlas occurs sometimes (Fig. 2I; data not shown). Occasional fusion of distal ribs, broadening of ossification centers of vertebral bodies within the thoracic region, and reduction and malformation of intervertebral discs may be secondary to the lack of segmentation in the lateral vertebral region (Fig. 2F,M,O). This was confirmed by analyzing cartilaginous preskeletons of Tbx18 mutant embryos at E14.5 (Fig. 2P-U). Again, pedicles in the cervical and thoracic region and proximal ribs, respectively, are expanded to form contiguous bands, whereas all other vertebral elements retain apparently normal segmentation (Fig. $2 \mathrm{Q}, \mathrm{U})$.

Thus, $T b \times 18^{-/-}$embryos are characterized by skeletal defects limited to the derivatives of the lateral sclerotome. Pedicles and proximal ribs derived from the posterior lateral sclerotome are expanded in the anterior body region. This might indicate that the sclerotome of Tbx $18^{-1-}$ embryos lacks properties of the anterior half and/or might have gained properties of the caudal half.

\section{Lateral sclerotome, but not other somitic compartments, is affected by loss of Tbx18 function}

The skeletal analysis of Tbx18 mutant embryos has pointed to a critical function of the gene in lateral sclerotome development. However, expression of Tbx18 in undifferentiated somites suggests that not only the sclerotome, but also other somitic compartments, could be affected by loss of $T b \times 18$ function. To determine differentiation of the somitic mesoderm into dermatome, myotome, and sclerotome in Tbx18 mutant embryos, we used molecular and histological markers to distinguish the various somite compartments at E10.5.

Myogenin is expressed in the myotomes in a repeating metameric pattern (Edmondson and Olson 1989). Pax3 is 
Bussen et al.

Figure 2. Morphology and skeletal defects of newborns and embryos mutant for Tbx18. $(A, B)$ External morphology. The $T b \times 18^{-/-}$pup $(B)$ has a shorter body axis than the wild type $(A) .(B-F)$ Hematoxylin-andeosin-stained sagittal sections of newborn $T b \times 18^{-/-}$ pups and wild-type littermates. The mutant $(D)$ shows a massive kink in the vertebral column of the thoracic region (arrow); the lung (1) is not inflated. Higher magnification of the thoracic vertebral column showing regular spacing between vertebral bodies $(\mathrm{vb})$ and intervertebral discs (iv) in the wild type $(E)$, and distorted nuclei pulposi (arrows) within thinner intervertebral discs in the mutant $(F) .(G-O)$ Skeletal preparations of $T b \times 18^{-/-}$newborns. Lateral view of whole skeletons $(G)$ and higher magnification of the cervical/upper thoracic $(H, I)$ and lumbar $(J, K)$ regions of wild-type and mutant pups. $(I)$ The arrow points to a small orifice for a spinal nerve within the pedicle band in the mutant. $(K)$ Note altered shape of pedicles $(\mathrm{p})$ in the mutant. $(L, M)$ Dorsal views showing smaller rib cage with ossification band in the proximal region (arrows) and fusions of distal ribs (arrowhead) in $T b \times 18^{-/-}$pups $(M) .(N, O)$ Ventral view of a wild-type $(N)$ and a $T b \times 18^{-/-}(O)$ thoracic region showing that rib heads remain separate in the mutant (arrows). (P-U) Alcian blue stainings of the cartilaginous preskeleton in whole E14.5 Tbx $18^{-/-}$embryos. Lateral views of upper cervical $(P, Q)$ and lumbar regions $(R, S)$; dorsal views of rib cages $(T, U)$ of wild type $(P, R, T)$ and $T b \times 18^{-/-}$embryos $(Q, S, U)$. Arrows point to expanded pedicles $(Q)$ and proximal ribs $(U)$ in mutant embryos.

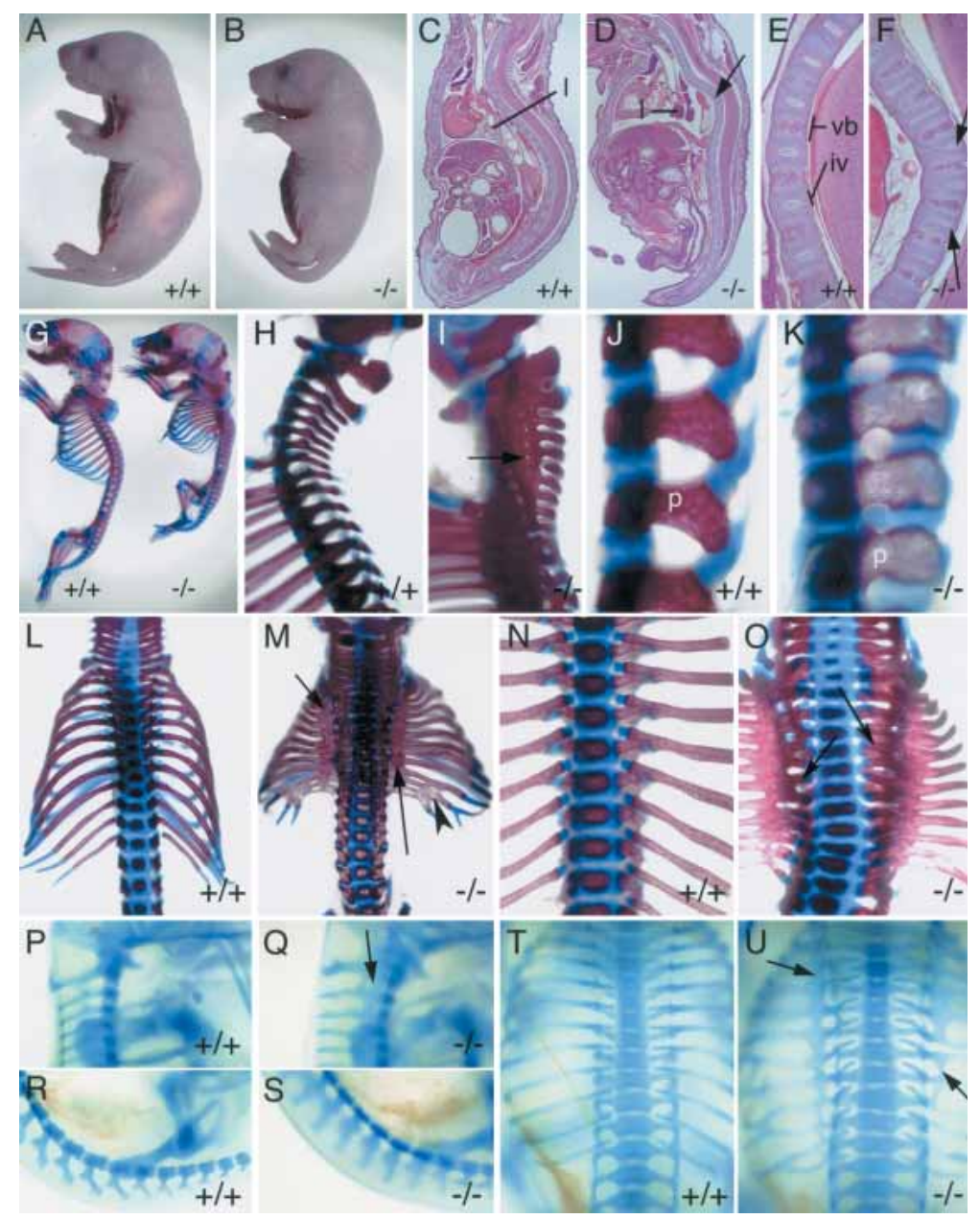

first expressed in newly forming somite; later it becomes restricted to the dermomyotome (Goulding et al. 1994). Paraxis is expressed in the anterior PSM, then in the newly formed somite and subsequently in the dermatome and dermomyotome (Burgess et al. 1995). Pax1 transcripts are expressed in ventromedial sclerotomal cells (Deutsch et al. 1991). Pax9 is expressed in the ventrolateral sclerotome compartment with a strong upregulation in the posterior somite half (Neubüser et al. 1995). Mox1 is expressed strongly in caudal but less strongly in cranial somite halves (Fig. 3A, panels a,c,e,g,i, k; Candia et al. 1992).

In situ hybridization analysis on whole E10.5 embryos revealed that expression of Myogenin, Pax3, Paraxis, and Pax1 is unchanged in Tbx18 ${ }^{-/-}$embryos (Fig. 3A, panels $\mathrm{b}, \mathrm{d}, \mathrm{f} ;$ data not shown). This suggests that the (dermo)myotome is not affected, and medial sclerotome is not expanded at the expense of lateral sclerotomal fates in the absence of $T b x 18$. Early expression of Pax 9 and Mox1 in newly formed somites is unaltered in mutants. However, the differential expression between anterior and posterior somite halves is progressively replaced by a more uniform and high expression (Fig. 3A, panels $\mathrm{h}, \mathrm{j}, \mathrm{l})$.

Consistent with the skeletal phenotype and altered ex- pression patterns of $\operatorname{Pax} 9$ and Mox1, we observed histological differences within the lateral sclerotome of Tbx $18^{-/-}$embryos. Histological stainings of parasagittal sections through the lateral sclerotome of the cervical region at E10.5 show a regular pattern of cell density differences between anterior and posterior somite halves in the wild type (Fig. 3B, panel a). In Tbx18 $8^{-/-}$embryos, cell densities between the two halves are indistinguishable (Fig. 3B, panel b).

Higher cell density of the posterior lateral sclerotome in the wild type is caused by a higher cellular proliferation rate in the posterior somite half (Fig. 3C). In E10.5 Tbx18 ${ }^{-/-}$embryos, the BrdU labeling index reflecting cellular proliferation rates of anterior halves has increased to the level of posterior halves in the lateral sclerotome of the cervical region (Fig. 3C, panel a). However, no differences in BrdU incorporation between wildtype and mutant embryos were noticed in anterior and posterior halves, respectively, of newly formed somites at E9.5 (Fig. 3C, panel b).

To address whether loss of $T b \times 18$ affects programmed cell death in the somitic mesoderm, we analyzed apoptosis in wild-type and mutant embryos (Fig. 3D). At E10.5, we observed increased apoptosis in the anterior lateral sclerotome of cervical regions of $\mathrm{Tb} 18^{-/-} \mathrm{em}$ - 

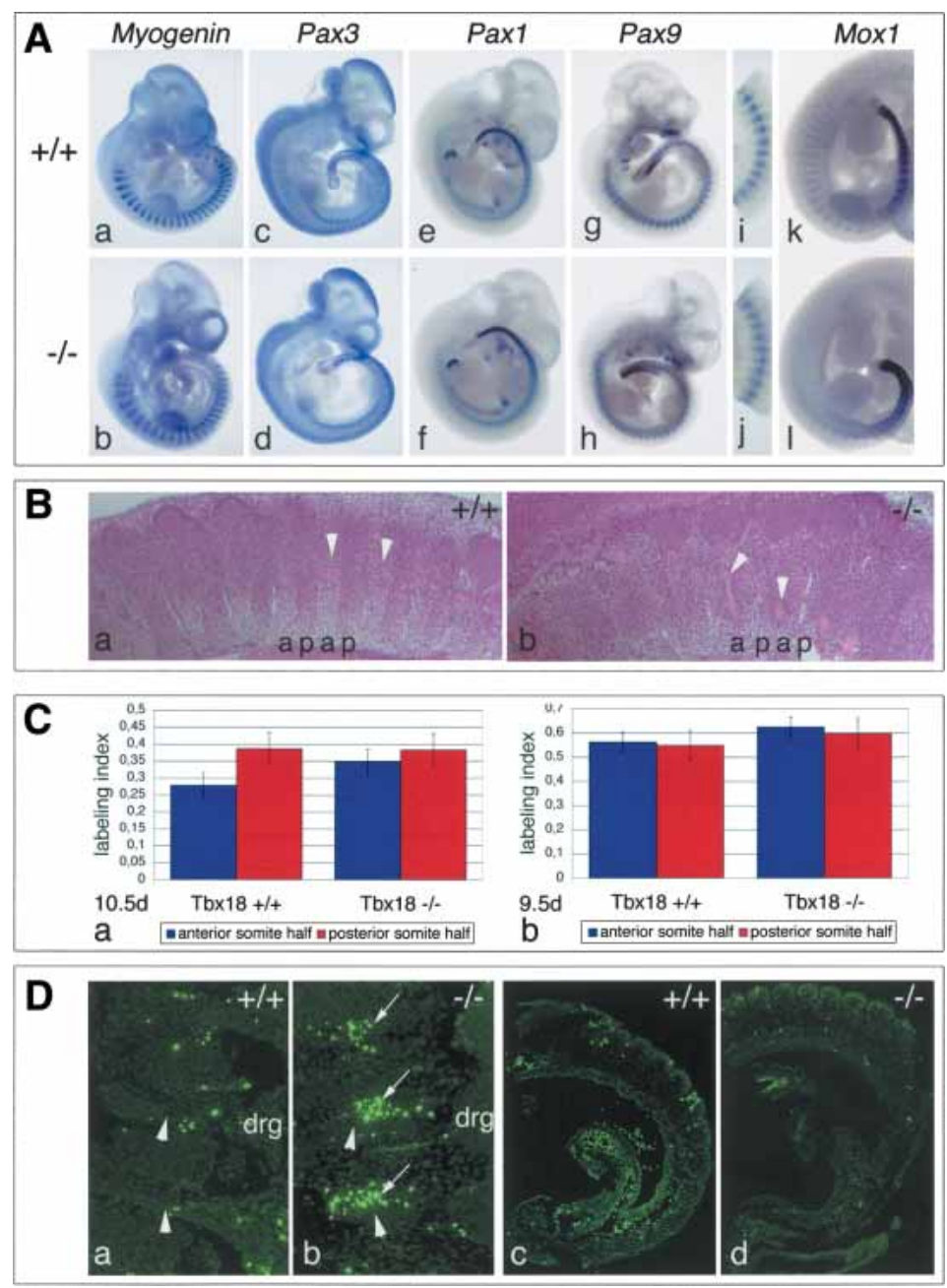

Figure 3. Somite development and differentiation in Tbx18 mutant embryos. (A) In situ hybridization analysis for markers of somite differentiation at E10.5, in the wild-type (panels $a, c, e, g, i, \mathrm{k}$ ) and in $T b \times 18^{-1-}$ mutants (panels $b, d, f, h, j, l)$. Markers for myotome (Myogenin, panel $b)$, dermomyotome (Pax3, panel $d)$, and ventral sclerotome (Pax1, panel $f)$ are unchanged in $T b \times 18^{-/-}$ embryos. Progressive loss of polarized Pax 9 (panels $g, h$, and higher magnification of thoracic somites in panels $i, j)$ and Mox1 (panels k,l) expression. (B) Histological analysis of sclerotome compartmentalization in cervical regions of $T b \times 18^{-/-}$embryos at E10.5. In the wild type (panel a), a regular pattern of less condensed anterior (a) and more condensed posterior (p) lateral sclerotomal cells is visible. (Panel b) In Tbx18 $18^{-/-}$embryos, cell densities are similar in both compartments. Arrowheads point to spinal nerves passing through anterior halves. $(C)$ Analysis of cell proliferation in somites of $T b \times 18^{-/-}$embryos. Labeling index is defined by the ratio of BrdU-positive cells to total cell number in the analyzed area. (Panel a) At E10.5d, labeling indices between anterior and posterior sclerotomal halves of cervical somites are clearly different in the wild type (anterior, $0.278 \pm 0.036$ vs. posterior, $0.386 \pm 0.048$ ). In $T b \times 18^{-/-}$embryos, cell proliferation in anterior somite halves as judged by the labeling index has almost reached the rate of posterior halves (anterior, $0.348 \pm 0.051$, vs. posterior, $0.383 \pm 0.076)$. The increase of proliferation between anterior halves of wild type and mutant is statistically significant $(p=0.0022)$. $($ Panel $b$ ) In forming somites at E9.5, no difference in cell proliferation was detected between anterior and posterior halves of wild-type (anterior, $0.561 \pm 0.091$; posterior, $0.548 \pm 0.094$ ) and $T b \times 18^{-/-}$embryos (anterior, $0.0624 \pm 0.041$; posterior, $0.599 \pm 0.062$ ), respectively. The overall increase in the mutant is not statistically relevant. $(D)$ Analysis of apoptosis in somites of Tbx18 $8^{-/-}$embryos. (Panels $\left.a, b\right)$ E10.5. Increased apopto-

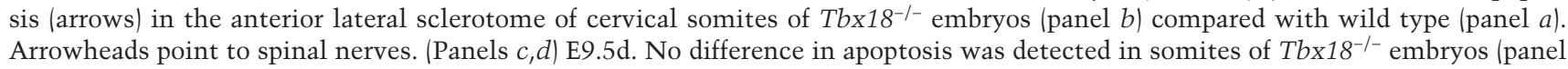
d), respectively.

bryos (Fig. 3D, panel b). Analysis of newly formed somites at E9.5 did not reveal any differences in apoptosis between mutant and wild type at this stage (Fig. 3D, panel d).

In summary, molecular and histological analysis of somite differentiation in Tbx18 mutant embryos suggest that $T b x 18$ might play a crucial role in the development of the lateral sclerotome. Anterior halves of the lateral sclerotome acquire features of posterior halves. In addition, lack of $T b x 18$ results in increased programmed cell death in the anterior sclerotomal compartment. Thus, Tbx18 might be important in maintaining anterior fates by repressing posterior somite (sclerotome) fates. Alternatively, Tbx18 might act indirectly by preventing cells from the posterior somite halves from migrating into the anterior halves. To distinguish these possibilities and to determine the genetic pathway in which Tbx18 acts, we used whole-mount in situ hybridization to analyze expression of markers for AP-somite polarity in Tbx18 mutant embryos, as well as expression of Tbx18 in somitogenesis mutants.

\section{AP-somite polarity is established but not maintained in Tbx18 mutant embryos}

Tbx18 shows polarized expression in anterior halves of prospective somites S0 and S-1 of the PSM and later in epithelial and maturing somites (Fig. 4A, panels a,b). Ex-

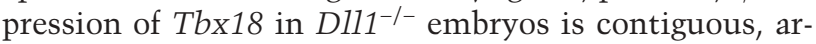
guing that the Delta/Notch pathway exerts a repressive function on $T b x 18$ expression in prospective and definitive posterior somite halves (Fig. 4A, panels c,d). Uncx4.1 might partly mediate DI11-repression, as indicated by contiguous expression of $\mathrm{Tbx} 18$ in somites of Uncx 4.1 $1^{-1-}$ embryos (Fig. 4A, panels g,h). Interestingly, the two PSM stripes of Tbx18 expression are preserved, suggesting that an additional factor is required to mediate D111-dependent repression in this domain. Pudgy is a natural mutant of the D113 gene in the mouse (Kusumi et al. 1998). Expression of Tbx18 in pu/pu embryos is fuzzy (Fig. 4A, panels e,f), supporting that D113-dependent processes are required to maintain distinct anterior and posterior somite compartments (Dunwoodie et al. 2002). 
Figure 4. Regulation and function of Tbx18 in anterior-posterior somite polarity. $(A)$ Whole-mount in situ hybridization analysis of Tbx18 expression in embryos with defects in somitogenesis at E10.5. (Panels $a, c, e, f$ ) Whole embryos. (Panels $b, d, f, h)$ Higher magnification of posterior trunk regions. (Panels $a, b$ ) In the wild type, Tbx18 expression is restricted to anterior halves of prospective and definitive somites. (Panels $c, d$ ) Tbx18 is expressed throughout the anterior PSM and somites in $D 111^{-/-}$embryos. (Panels $e, f$ ) Expression boundaries are fuzzy in pudgy/pudgy (Dl13-/-) embryos. (Panels $g, h)$ In Uncx $4.1^{-1-}$ embryos, there is continuous expression of Tbx18 in posterior somite halves but not in the PSM region (arrows). (B) Whole-mount in situ hybridization analysis of expression of markers for early AP-somite polarity in posterior trunks at E10.5. Markers as indicated in the figure and described in the text are not changed in $T b \times 18^{-/-}$(panels $\left.b, d, f, h, i, l, n, p\right)$ compared with wild-type (panels $a, c, e, g, i, k, m, o$ ) embryos. (E B2) EphrinB2. (C) In situ hybridization analysis of Uncx4.1 expression at E10.5 in $\mathrm{Tb} \times 18^{-/-}$embryos. Whole embryos (panels $a, b$ ), posterior trunk regions (panels $c, d$ ), and sections of cervical somite regions (panels $e, f$ ) with anterior to the right. (Panels $a, c, e$ ) In the wild type, Uncx4.1 expression is confined to posterior somite halves. (Panels $b, d, f)$ In Tbx18 $18^{-1-}$ embryos, Uncx4.1 expression progressively expands into the anterior somite compartment. $(D)$ Analysis of peripheral nervous system development in Tbx18 $18^{-/-}$embryos. (Panels $a, b$ ) HEstained parasagittal sections of cervical regions at E13.5. In the wild type (panel $a$ ), dorsal root ganglia (drg) are clearly separated; in $T b \times 18^{-/-}$embryos (panel b), they are fused. (Panels $c-f$ ) Antineurofilament staining to reveal the organization of spinal nerve projections at E10.5. In the wild type (panels $c, e$ ), spinal nerves traverse the anterior half of each mature somite, and in the mutant some spinal nerves are lacking (arrows in panel d); partly, the ones present appear thinner than in the wild type (arrows and arrowheads in panel fl, particularly at their base.

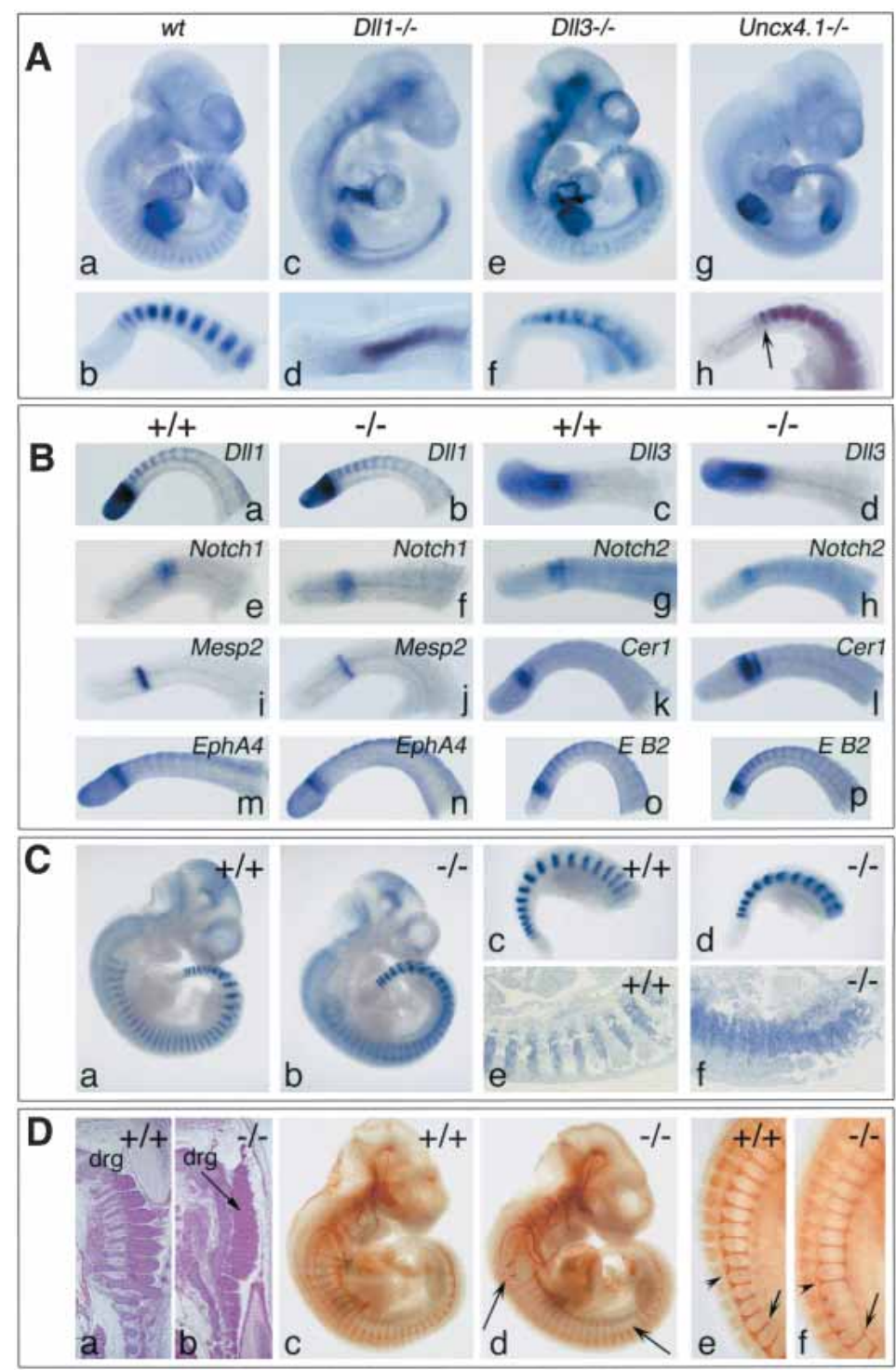

To confirm whether Tbx18 indeed acts downstream of the Dll/Notch-Mesp2 network, we analyzed expression of markers for early AP-somite polarity in Tbx18 mutant embryos.

Cer1 is expressed in anterior halves of forming somites S-1 and S0 and in newly epithelialized somites (Biben et al. 1998). EphA4 has an additional expression domain in the posterior PSM (Nieto et al. 1992). Mesp2 expression is dynamic in somite $\mathrm{S}-1$, where it becomes progressively restricted to the prospective anterior somite half (Saga et al. 1997). Dll1 expression is found in the tailbud, the PSM, and in caudal halves of forming and epithelial somites (Bettenhausen et al. 1995). Dll3 expression is confined to the PSM and the anterior halves of forming somites. Down-regulation quickly occurs after epithelial somites have formed (Dunwoodie et al. 1997). Notch1 is expressed in the anterior PSM. Notch2 is coexpressed with Notch1 in the anterior PSM but is also detected in anterior halves of forming somites (Williams et al. 1995).
Ephrin B2 expression is found in the anterior PSM and in posterior somite halves. Somitic expression gradually weakens with somite differentiation (Wang and Anderson 1997).

Expression of all of these genes was not affected in Tbx $18^{-/-}$embryos (Fig. 4B), strongly suggesting that establishment of AP polarity in somites is independent from $T b x 18$. To study whether Tbx18 plays a role in maintaining this polarity, we analyzed expression of Uncx4.1 in Tbx18 mutant embryos (Fig. 4C). Expression

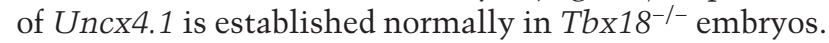
However, starting from somites IV to V, the anterior expression boundary of Uncx4.1 becomes blurred. Concomitantly, the Uncx4.1 expression stripe progressively expands anteriorly, leading to homogenous expression of Uncx4.1 throughout cervical and thoracic somites (Fig. 4B, panels d,f). Normal Uncx4.1 expression in newly formed somites strongly argues that $T b \times 18$ does not control somite polarization by transcriptional repression of 
Uncx4.1. Rather, Tbx18 might prevent immigration of posterior somite cells into the anterior compartment during subsequent somite development.

At this point, we lack markers to determine the fate of cells from anterior somite halves. LacZ expression from the Tbx18 mutant allele could not be used because $\beta$-galactosidase staining activity does not recapitulate the Tbx18 expression pattern (data not shown).

In the wild type, the polarity of the somite patterns the adjacent tissues including the neural crest. Mediated by repulsive forces from the posterior somite half, neural crest cells exclusively migrate through the anterior somitic half, resulting in a metameric pattern of spinal ganglia and nerves (Keynes and Stern 1984). In Tbx18 ${ }^{-/-}$ embryos, the dorsal root ganglia partly fuse, a process that can be observed from E10.5 onward (Fig. 4D, panel b). Immunohistochemical detection of neurofilament at this stage reveals a partial loss of spinal nerve projections or deflections from their path through anterior somite halves (Fig. 4D, panel d,f). Partly, spinal nerves transversing anterior somite halves appear thinner than in the wild type, suggesting that repulsive forces from posterior somite halves have spread anteriorly (arrows and arrowheads in Fig. 4D, panel f). This agrees with our finding from Uncx4.1 expression that posterior somite halves expand anteriorly in the mutant.

In summary, our analysis of AP-somite polarity in Tbx18 mutant embryos clearly points to a crucial function of this transcription factor in maintaining rather than establishing somite compartmentalization.

\section{Tbx18 is sufficient to change anterior-posterior somite compartmentalization}

The histological and molecular analysis of Tbx18 mutant embryos has unambiguously demonstrated a requirement for Tbx18 in maintaining AP-somite compartmentalization and mediating lateral sclerotome development. To investigate whether $T b x 18$ is sufficient to promote the formation of the anterior somite compartment, we generated transgenic mice ectopically expressing Tbx18 throughout somites. We fused the Tbx18 coding region to the msd-enhancer from the Delta-like1 gene, followed by a GFP-tag for detection of the induced RNA. The msd-enhancer directs heterologous gene expression in the anterior PSM, newly formed somites, and myotomes of differentiating somites. Thus, overexpression in the anterior somite halves and misexpression in the posterior halves may be achieved.

Ten transgenic founder mice were obtained. All bred and transmitted the transgene to the offspring. None of the hemizygous carriers showed external morphological changes indicative of skeletal malformations. In order to detect more subtle phenotypes, we analyzed skeletal preparations of E18.5 embryos from matings of hemizygous transgenic males with wild-type females. In two lines (line 2 and line 20), we found in the expected Mendelian ratio weak skeletal changes compatible with a perturbed AP polarity of the lateral sclerotome. In situ hybridization analysis of GFP-expression confirmed transgene expression at E10.5 in hemizygous embryos of either line. As expected, msd-mediated transgene expression was restricted to the PSM, newly formed somites, and the myotome of differentiating somites (Fig. 5A, panels b,c).

To further analyze the effect of forced Tbx18 expression on the phenotypic outcome, we studied hemi- and homozygous transgenic mice of lines 2 and 20. Because we reasoned that high transgene expression might result in strong skeletal phenotypes incompatible with postnatal life, we restricted our skeletal analysis to E18.5 embryos derived from hemizygous intercrosses of line 2 and line 20, respectively (Fig. 5B). Homozygosity was ascertained by quantitative PCR (see Materials and Methods). Doubling transgene doses led to more severe skeletal phenotypes in both lines. In hemizygous embryos of transgenic msd::Tbx18 line 2, proximal ribs and pedicles are slightly thinner, as in the wild-type control (Fig. 5B, panels $b, g, l$, arrows). Homozygotes of this line show more pronounced thinning of both elements. In some of the ribs and vertebrae, partial loss of pedicles and proximal ribs occurs (Fig. 5B, panels c,h,m, arrows). The skeletal phenotype of hemizygous transgenic embryos of line 20 is similar to that of homozygous transgenics of line 2 (Fig. 5B, panels d,i,n). Homozygous transgenics of msd::Tbx18 line 20 exhibit the most severe skeletal malformations. Pedicles and proximal ribs all along the vertebral column are largely reduced or absent (Fig. 5B, panels e,j,o, arrows). As a secondary consequence, transgenic embryos show severe lordosis of the vertebral column in the thoracic region, a small and distorted rib cage, and a reduced body length (Fig. 5B, panels e).

Contrary to the $T b x 18$ loss-of-function phenotype, elements derived from the posterior compartment of the lateral sclerotome are reduced in transgenic embryos. To confirm that the phenotypic consequences of $T b x 18$ misexpression are restricted to changes in somite and lateral sclerotome AP polarization, respectively, we analyzed expression of differentiation markers for myotome (Myogenin) and sclerotome (Pax9, Uncx4.1), the pan-somite marker Mox1, and early AP-polarity markers at E10.5 by RNA in situ hybridization. Because phenotypic changes are most pronounced in the msd::Tbx18 line 20, we only used homozygous embryos of this genotype for our molecular analysis. Myogenin expression is unchanged in the transgenic embryos, arguing that differentiation of myotome and (and most likely dermatome) is not affected, although misexpression of $T b \times 18$ is targeted to these differentiated tissues as well as to their precursor tissues (Fig. 5C, panel g). Mox1 expression is established normally, but polarized expression is progressively replaced by a low and uniform expression pattern (Fig. 5C, panel h). Pax9 expression is unchanged in newly forming somites of transgenic embryos. However, posterior stripes with strong expression progressively restrict to the posterior somite border (Fig. 5C, panel i). Uncx4.1 expression in newly formed somites starts normally but then becomes down-regulated and confined to a thin stripe at the posterior somite border in transgenic embryos (Fig. 5C, panel j). We also analyzed expression of 
Figure 5. Ectopic expression of Tbx18 in somites leads to defects in AP-somite polarity and lateral sclerotome development. (A) In situ hybridization analysis of expression of Tbx18-GFP-fusion transcripts in E10.5 transgenic embryos. Embryos hemizygous of msd::Tbx18 line \#2 (panel b) and msd::Tbx18 line \#20 (panel c) show transgene expression in the PSM, the somitic mesoderm, and the myotome. (B) Skeletal malformations in msd:: tbx18 transgenic at E18.5. Genotypes of embryos are indicated above each row. (Panels $a-e$ ) Lateral views of whole skeletal preparations of wild-type and transgenic embryos. Arrow in panel $e$ points to reduced pedicles along the vertebral column. (Panels $f-i$ ) Higher magnification of the lumbar region of the skeletal preparations shown in panels $a-e$. Arrows in panels $h, i$, and $j$ point to reduced pedicles. (Panels $k-o)$ Higher magnification of the rib cage in a dorsal view of the skeletal preparations shown in panels $a-e$; arrows in $1, m$, and $o$ point to reduced or missing proximal ribs. (C) In situ hybridization analysis of somite differentiation and polarization in homozygotes of $\mathrm{msd}:: \mathrm{Tbx} 18$ (tg/tg) line \#20 at E10.5. Genotypes are indicated in the figure. (Panel $g$ ) Myogenin expression is unchanged. (Panel h) Mox1 expression in posterior somite halves is reduced to a thin stripe in the interlimb region of transgenic embryos. (Panel i) The strong posterior $\operatorname{Pax} 9$ expression domain is reduced in the interlimb region of $\mathrm{msd}:: \mathrm{Tbx} 18$ transgenic embryos. Anterior is up. (Panel j) Uncx4.1 expression analysis reveals reduction of posterior somite compartments in transgenic embryos. Note that Uncx4.1 expression is normal in the most recently formed five to six somites. (Panel k) D111 expression in the PSM and in the most recently formed three somites is unchanged in transgenic embryos, then expression gets progressively weaker. (Panel 1) EphrinB2 (E B2) expression is normal in the first four to five somites of transgenic embryos, then it gets weaker. $(D)$ Antineurofilament staining to reveal the organization of spinal nerve projections in homozygotes of msd::Tbx18 line \#20 at E10.5. The metameric organization of spinal nerve projections is maintained in transgenic embryos (panel $b$ ); however, they appear less bundled (panel $d$ ). Higher magnification of the interlimb region of the embryos shown in panels $a$ and $b$. Anterior is to the left. (Panel $d$ ) Arrows in the small inset figure point to colaterals leaving the nerve.

Dl11 and EphrinB2, both of which are expressed in posterior halves of newly formed somites (Fig. 5C, panels $\mathrm{e}, \mathrm{f})$. Expression of both genes was found to be unchanged in early somites. In older somites (>SIII) of some transgenic embryos, Dll1 and EphrinB2 expression appear weaker (Fig. 5C, panels k,1). This suggests that ectopic expression of Tbx18 indeed results in changes of APsomite and lateral sclerotome polarity but does not affect somite development in general.

Reduction of posterior somite compartments should lead to altered spinal nerve projection through the somites. Antineurofilament staining in homozygous embryos at E10.5 shows that spinal nerves are less bundled, with single axons projecting even laterally away from the bundle (Fig. 5D, panel b, arrows), strongly arguing for a reduction of repulsive forces from posterior somite compartments.

In summary, misexpression of Tbx18 in newly formed somites leads to expansion of the anterior and a reduction of the posterior somite compartment. The conse- quent change in the subdivision of the lateral sclerotome manifests itself as a partial or complete reduction of pedicles and proximal ribs. Ectopic expression of Tbx18 does not affect the initial specification of anterior and posterior somite halves. Hence, $T b \times 18$ is not only required to maintain AP-somite compartmentalization, but is also sufficient to expand anterior compartments after their initial specification.

\section{Discussion}

The segmental organization of the axial skeleton and peripheral nervous system of vertebrates depends on the subdivision of somites into anterior and posterior compartments. This study shows that specification and maintenance of anterior and posterior somite halves are separate processes with distinct molecular requirements and that the T-box transcription factor Tbx18 maintains the integrity of the anterior somite compartment. Thus, Tbx18 mediates maintenance of AP-somite compart- 
mentalization, lateral sclerotome development, and resegmentation.

\section{Tbx18 maintains rather than specifies anterior somite compartments}

Loss of Tbx18 function results in skeletal defects characterized by expansion of pedicles and proximal ribs, which are derived from posterior lateral sclerotome (Aoyama and Asamato 2000; Huang et al. 2000). These defects resemble the results of experimental somite manipulations in chick embryos where tissue blocks consisting of multiple caudal somite halves were used to replace normal somitic mesoderm. In contrast, ectopic expression of $T b x 18$ throughout somites leads to a dosedependent reduction of these elements resembling the consequences of combining multiple anterior somite halves in chick embryos (Goldstein and Kalcheim 1992). Together, the loss and ectopic expression phenotypes indicate that Tbx18 is both necessary and sufficient to promote the development of anterior somite half derivatives.

Tbx18 could either specify anterior somite fates, or it could be required to maintain the integrity of the anterior somite compartment. In the first alternative, loss of Tbx18 function would result in acquirement of a posterior somite half "default" state in anterior halves; ectopic expression of $T b x 18$ in posterior somite halves would respecify them into anterior halves. In the second possibility, the primary role of $T b x 18$ could be to control separation of cells normally residing in different somite compartments. We favor a primary role for $T b x 18$ in maintaining the AP subdivison of somites for the following reasons.

First, somite polarity of newly formed somites is unchanged in $\mathrm{Tb} \times 18^{-/-}$embryos, indicating that anterior and posterior somite halves are correctly specified by the Delta/Notch-Mesp2 network. Thus, Tbx18 acts downstream of the Delta/Notch and Mesp2 network that establishes AP polarity within somites. In Dll1 mutant embryos, Tbx18 expression is contiguous in the anterior PSM and the somitic mesoderm. Thus, the restricted expression of $T b x 18$ in anterior compartments appears to be achieved by Dll1-mediated repression in posterior somite halves.

Second, expression of a gene (Uncx4.1) with polarized expression along the body axis progressively expands during somite differentiation, leading to expression throughout the somite in the cervical region in $\mathrm{Tb} \times 18^{-/-}$ embryos. This indicates a progressive reduction of anterior somite compartments.

Third, expansion of lateral vertebral elements and proximal ribs is essentially restricted to cervical and thoracic levels. This phenotype is not compatible with early loss of anterior somite half specification. In such a case, as exemplified by the Mesp2 mutant (Saga et al. 1997), the metameric organization should be lost along the entire vertebral column. The progressive, thus slow, nature of expansion of posterior somite compartments may account for the stronger phenotype in the anterior trunk region. All of these findings point to the fact that $T b x 18$ neither controls differentiation of somites nor specifies or influences anterior somite half development in newly forming somites.

Cells within the anterior compartment are not characterized by increased apoptosis in the Tbx18 mutant. The lack of suitable markers did not allow us to follow their fate. Possibly, these cells also lose their compartment restriction and move posteriorly. Alternatively, cells from anterior somite halves remain restricted to their original anterior somite halves. Circumstantial evidence for such a scenario may come from our analysis of apoptotic cell death in cervical somites. An increase of programmed cell death was restricted to the anterior lateral sclerotome in the mutant, suggesting that anterior cells might still be confined to their original compartment. However, we cannot exclude that cells from the posterior half now exposed to a new environment are subject to increased apoptosis. Clearly, future experiments need to address the questions of migration of cells from anterior and posterior somite halves by cell labeling experiments in vivo.

The results of our analysis of msd::Tbx18 transgenic embryos further supports the idea that $T b x 18$ regulates the maintenance of distinct anterior and posterior compartments rather than specifying anterior somite halves, because somite compartments are normally established but posterior halves are progressively reduced. The msd-enhancer/promotor used in this experiment mediates transgene expression throughout the somite. It is unclear whether overexpression of $T b x 18$ in anterior somite halves, misexpression in posterior somite halves, or the combined effect of both accounts for the reduction of posterior somite compartments in transgenic embryos. Without having deciphered the molecular pathways regulated by Uncx4.1 and $T b x 18$, it is difficult to imagine what consequences that coexpression of both genes in one cell might have. However, the massive reduction of posterior somite compartments in transgenic embryos raises the possibility that forced overexpression of Tbx18 may override posterior somite specification.

Recombination and transplantation experiments in the chick have shown that anterior and posterior somite halves display differential adhesive properties (Stern and Keynes 1987). Anterior and posterior cells only mix with cells from like somite halves, whereas somite cells from unlike halves maintain a boundary between them. Analysis of $\mathrm{N}$-Cadherin and Cadherin 11 double mutant mice has confirmed that the two somite halves display distinct adhesive properties (Horikawa et al. 1999). It is tempting to speculate that $T b x 18$ regulates integrity of anterior somite halves by regulating the selective adhesion of cells within them. Posterior cells might express their own adhesion system, or alternatively, they might not selectively adhere to each other but might be prevented from invading the anterior compartment. Loss of Tbx18 function could result in decreased adhesion among anterior cells, allowing posterior cells to invade. Conversely, misexpression of Tbx18 would confer new 
adhesion properties to posterior somite cells, making them stick to other anterior-like cells.

Instead, or in addition, Tbx18 might regulate a system of repulsive forces exerted from the anterior onto the posterior compartment. Such a system is exemplified by the Eph-Ephrin pair of transmembrane ligand and receptor that governs the selective migration of spinal nerves through anterior somite halves. Here, posterior somite halves express a repulsive molecule that is sensed by the receptor expressed in axonal membranes (Wang and Anderson 1997). Elucidation of the molecular mechanism(s) maintaining AP-somite subdivision will be aided by comparison of mRNA populations of Tbx18 mutant and wild-type somites.

The finding that the anterior compartment has lost Tbx18 but has gained Uncx4.1 function in the mutant complicates analysis of the later function of $T b \times 18$ in the lateral sclerotome. Our analysis suggests that $T b \times 18$ maintains cells in the anterior lateral sclerotome by preventing apoptotic cell death, but it could not reveal whether Tbx18 might additionally regulate cell proliferation. Possibly, Tbx18 represses cell proliferation in anterior somites and lateral sclerotome. Similarly, Uncx4.1 may regulate cell proliferation in posterior somite compartments. Thus, antagonistic action of Uncx4.1 and Tbx18 might be responsible for higher cell density in the posterior half of the lateral sclerotome from which proximal ribs and pedicles derive.

\section{Concerted action of Uncx 4.1 and Tbx18 maintains the separation of anterior and posterior somite compartments}

The comparison of the phenotypic consequences of loss of Uncx4.1 function (Leitges et al. 2000; Mansouri et al. 2000) with that of gain and loss of $T b x 18$, as presented in this report, argues that the combined action of this pair of transcription factors regulates part of the program of AP-somite compartmentalization and lateral sclerotome differentiation.

Gene-targeting experiments have shown that Uncx4.1 is specifically required for the development of pedicles and proximal ribs (Mansouri et al. 1997; Neidhardt et al. 1997). Misexpression of $T b x 18$ in posterior somite halves results in reduction of pedicles and proximal ribs. Thus, the gain-of-function phenotype of msd::Tbx18 transgenic mice resembles the loss-of-function phenotype of Uncx4.1 mice. In a sense, the two msd::Tbx18 transgenic lines behave like hypomorphic alleles of Uncx4.1.

Our molecular analysis provides evidence that the functional antagonism between Uncx4.1 and Tbx18 can be explained by molecular cross regulation. In Uncx 4.1 mutants, Tbx18 expression is contiguous in the somitic mesoderm. Thus, Dll1-dependent anterior restriction of Tbx18 expression is achieved by Uncx4.1-mediated posterior repression. Of course, we cannot state whether Uncx 4.1 directly represses Tbx18 expression or whether Uncx 4.1 acts indirectly by activating a downstream repressor. Expression of a candidate downstream repressor should be confined to posterior somite halves like that of
Uncx4.1 itself. To date, a second transcription factor exhibiting such an expression pattern has not been reported.

Maintenance of posterior restricted expression of Uncx4.1 throughout somitic differentiation argues that Uncx4.1, like $T b x 18$, fulfills a maintenance function in AP-somite compartmentalization. Continuous Uncx4.1 expression is required to confine $T b x 18$ expression to anterior somite halves.

Derepression of Tbx18 in posterior somite halves of Uncx4.1 mutants provides a molecular explanation for the similarity of skeletal phenotypes of Uncx4.1 mutants and msd::Tbx18 transgenic mice. Indeed, Uncx $4.1^{-1-}$ embryos can be considered as "transgenic" embryos with misexpression of $T b x 18$ in posterior somite halves. Although experimental evidence is lacking, it is tempting to speculate that misexpression of Uncx4.1 in anterior somite halves should result in skeletal malformations similar to those in Tbx18 mutant mice due to repression of Tbx18 and subsequent expansion of the posterior somite halves.

In summary, we suggest that Uncx4.1 and Tbx18 together are pivotal to the maintenance of AP-somite polarization. After initial specification of anterior and posterior somite halves by the Notch/Delta and Mesp2 network, this pair of transcription factors maintains somite compartmentalization by preventing migration of anterior or posterior cells into the neighboring compartment. This allows the subdivision of the lateral sclerotome and development of a functional musculoskeletal system.

\section{Materials and methods}

Generation of Tbx18 mutant mice

To clone the mouse Tbx18 locus, we screened a 129/Ola genomic cosmid library (obtained from the Resourcenzentrum Berlin) using the mouse cDNA (Kraus et al. 2001) as a probe. Three independent cosmid clones were purified. A $16.5-\mathrm{kb}$ EcoRI fragment harboring the $5^{\prime}$-region of the Tbx18 transcription unit was subcloned from one of them and characterized by restriction and exon mapping. To generate a targeting construct allowing inactivation of the Tbx18 gene, we inserted an IRES.lacZ fragment followed by a loxP-flanked neo-cassette into a NotI site located in the $5^{\prime}$-untranslated region of the first exon, flanked by two homology regions of $\sim 6 \mathrm{~kb}$ derived from the EcoRI subfragment (Fig. 1A). With this construction, a short fragment harboring the rest of exon 1 with the $5^{\prime}$-translated region was deleted, ensuring the generation of a null allele. The targeting vector was linearized at a unique SalI site and electroporated in ES cells of $129 \mathrm{~Sv} / \mathrm{ImJ}$ genotype. One hundred eightyfive G418 resistant ES cell clones were screened for homologous recombination in the Tbx18 locus by Southern blot analysis. Eight ES cell clones proved to be correctly targeted and were subsequently used for microinjection into FVB mouse blastocysts. Fifteen chimeric males were obtained and mated to NMRI females. Two chimeras gave germ-line transmission. F1 heterozygous males were crossed to NMRI females, heterozygous offspring intercrossed, and embryos and newborns analyzed for phenotypic alterations. Heterozygous mice were mated with ZP3::cre mice to remove the PGK.neo-cassette by cre-mediated recombination between loxP sites in the female germ line (de Vries et al. 2000). Mice homozygous for this 
Tbx18sneo allele were phenotypically indistinguishable from mice carrying the allele with the PGK.neo-cassette.

\section{Genotyping of Tbx18 mutant mice}

Genotypic characterization of ES cells, embryos, and adult mice was done by Southern blot analysis of restriction digested genomic DNA. DNA was derived from ES cells, embryonic yolk sacs, and adult tails, and hybridized with probes distinguishing wild-type and mutant alleles (Fig. 1A). The $5^{\prime}$-probe is a $1.5-\mathrm{kb}$ PCR fragment from the genomic region adjacent but outside the targeting vector that was amplified from the cosmid DNA using sequence information from the mouse genome (primers 458 [ $5^{\prime}$ ATGAATTCCCGGCACATTTGAAATACAG-3'] and 460 [5'ATGAATTCGGGATCTTCTAGCACAGTTC- ${ }^{\prime}$ ]). This probe recognizes a $21-\mathrm{kb}$ EcoRV fragment in the wild type and a $15-\mathrm{kb}$ EcoRV fragment in the mutant. The $5^{\prime}$-internal probe, a $1.3-\mathrm{kb}$ ApaI fragment from the left homology arm, detects a 16-kb EcoRI fragment in the wild type and a 7-kb EcoRI fragment in the mutant allele. The 3 '-probe used for routine genotyping of embryos and mice, a 1.5-kb EcoRV fragment, detects a 16-kb EcoRI fragment in the wild type and an $8.5-\mathrm{kb}$ EcoRI fragment in the targeted allele (Fig. 1B).

In addition, a PCR protocol was established to speed up genotyping of Tbx18 mutant embryos and mice. Primers 487 (sense, 5'-GCGCGGAAAAGGGCTCGG-3') and 231 (antisense, 5'CCGGCTTTGGTGATGATC-3') amplify a 700-bp fragment from the wild-type allele, and primers 581 (sense, $5^{\prime}$-CAGCC GCTACAGTCAACAG-3') and 231 amplify a 2500-bp fragment from the Tbx18 mutant allele (Fig. 1A,C).

\section{Generation of msd:: Tbx18 transgenic mice}

The mesoderm-specific promoter msd is a 1495-bp FokI fragment fused with the minimal promoter of Dll1 containing the first exon as previously described (Beckers et al. 2000). This msd fragment was ligated to an XhoI-DraI fragment of the Tbx18 cDNA harboring the entire open reading frame in addition to $235 \mathrm{bp}$ of the $5^{\prime}$-untranslated region (AF306666; Kraus et al. 2001). At the 3 '-end of the Tbx18 cDNA, a SmaI-AflII fragment from pd1EGFP-N1 (Clontech \#6073-1) harboring d1EGFP as an RNA tag followed by a SV40 polyadenylation signal was fused. Integrity of the transgene was verified by sequencing. Transgenic mice were generated by injecting the linearized construct without vector sequences into the pronuclei of FVB fertilized eggs according to standard procedures.

\section{Genotyping of Tbx18 transgenic mice}

Genomic DNA was isolated either from tails of adult mice or from yolk sacs of embryos at different developmental stages. The presence of the msd::Tbx18 transgene was verified by PCR with primers 557 (5'-GGACAACAAGAGATACAGGTA-3') and $558\left(5^{\prime}\right.$-TCTGATAGGCAGTGACAGTTG-3'), resulting in a 500-bp product. Hemizygous and homozygous embryos were distinguished by quantitative PCR against the internal standard HPRT (primers 561，5'-CACAGGACTAGAACACCT-3' and 562, 5'-GCTGGTGAAAAGGACCTC-3').

\section{Histological analysis}

Embryos for histological analysis were fixed in Bouin's fixative, paraffin embedded, and sectioned to $10 \mu \mathrm{m}$. Sections were stained with hematoxylin and eosin.

\section{Skeletal preparations of embryos and newborn mice}

Skeletal preparations of embryos and newborns were performed as previously described (Mallo and Brändlin 1997). Embryos and mice were fixed in $95 \%$ ethanol at least overnight. Then, the cartilage staining was done for $2 \mathrm{~d}$ in Alcian blue solution (150 $\mathrm{mg} / \mathrm{L}$ Alcian blue $8 \mathrm{GX}$ in $80 \%$ ethanol $/ 20 \%$ acetic acid). Embryos were rinsed and postfixed overnight again in $95 \%$ ethanol. E14.5 embryos were transferred in methanol and cleared in benzylbenzoate/benzylalcohol (2:1). Older stages were cleared in $2 \% \mathrm{KOH}$ for $1-2 \mathrm{~h}$ at room temperature. Bones were stained with Alizarin red $(50 \mathrm{mg} / \mathrm{L}$ Alizarin red $\mathrm{S}$ in $0.5 \% \mathrm{KOH})$ for several hours to overnight at room temperature. A second clearing was performed using $0.25 \% \mathrm{KOH}$ until the soft tissues became transparent. Following this incubation, the embryos were stepwise transferred to $30 \%$ glycerol.

\section{Proliferation and apoptosis assays}

Cell proliferation in tissues of E9.5 and E10.5 embryos was investigated by detection of incorporated BrdU similar to published protocols (Mansouri et al. 2000). In brief, Tbx18 heterozygous females mated to heterozygous males were injected with bromodeoxyuridine solution (Roche) at $100 \mu \mathrm{g} / \mathrm{g}$ body weight at the day of the conception. Embryos were recovered after $1 \mathrm{~h}$, fixed in 4\% paraformaldehyde, and processed via methanol and isopropanol into paraffin. Five-micrometer serial sections were cut and processed for staining. Epitopes were recovered by boiling the slides for $15 \mathrm{~min}$ in unmasking solution (VectorLabs) before endogenous peroxidase activity was blocked with $\mathrm{H}_{2} \mathrm{O}_{2}$. The sections were treated with mouse-on-mouse blocking reagent according to the manufacturer (VectorLabs) before the antigen was detected by successive incubations with anti-BrdU antibody (1:200, Roche), biotinylated anti-mouse IgG (VectorLabs), and VectastainABC (VectorLab) reagent. The detection reaction was performed using diaminobenzidine and hydrogen peroxide as substrates.

Three to four embryos of each genotype and stage were used in this study; at least 16 somites of each genotype and stage were analyzed. At E10.5, cervical somites were analyzed, whereas at E9.5, the first 10-12 somites were considered. The BrdU-labeling rate was defined as the number of BrdU-positive nuclei relative to the total number of nuclei as detected by DAPI counterstain. The mean values and standard deviation were determined and the Student's $t$-test was performed to test for statistical relevance.

Detection of apoptotic cells in paraffin sections of E9.5 and E10.5 embryos was based on modification of genomic DNA using terminal deoxynucleotidyl transferase (TUNEL assay) and indirect detection of positive cells by fluorescein-conjugated antidigoxigenin antibody. The procedure followed exactly the recommendation of the manufacturer (Serologicals Corporation) of the ApopTag kit used.

\section{In situ hybridization analysis}

Whole-mount in situ hybridization was performed following a standard procedure with digoxigenin-labeled antisense riboprobes (Wilkinson 1992). The probes used were Cer1 (Biben et al. 1998), Dll1 (Bettenhausen et al. 1995), D113 (Kusumi et al. 1998), EphA4 (Nieto et al. 1992), Ephrin B2 (Wang and Anderson 1997), Mesp2 (Saga et al. 1997), Mox1 (Candia et al. 1992), Myogenin (Edmondson and Olson 1989), Notch1 (Conlon et al. 1995), Notch2 (Weinmaster et al. 1992), Paraxis (Burgess et al. 1995), Pax1 (Deutsch et al. 1991), Pax3 (Goulding et al. 1994), Pax9 (Neubüser et al. 1995), Tbx18 (Kraus et al. 2001), and 
Uncx4.1 (Neidhardt et al. 1997). A GFP-specific riboprobe was generated from a BamHI/NotI fragment from pd1EGFP-N1 subcloned into pBluescriptIIKS (Stratagene) using T7 RNA polymerase. Stained specimens were transferred in 50\% glycerol prior to documentation.

In situ hybridization on 10 - $\mu \mathrm{m}$ paraffin sections was done essentially as described (Lescher et al. 1998).

\section{Neurofilament staining}

Whole-mount immunohistochemistry at E10.5 with 2H3 antineurofilament antibody (from Developmental Studies Hybridoma Bank) was performed essentially as described (Swiatek and Gridley 1993). However, embryos were incubated in ProteinaseK (10 $\mu \mathrm{g} / \mathrm{mL}$ for $20 \mathrm{~min}$ on ice) to increase penetration of antibodies.

\section{Documentation}

Whole-mount specimens were photographed on Leica M420 with Fujix digital camera HC-300Z, sections on Leica Axioplan with ProgRes C14 digital camera. All images were processed in Adobe Photoshop 7.0.

\section{Acknowledgments}

We thank Bénédicte Haenig for excellent technical assistance, and Ahmed Mansouri, Peter Gruss, Eric Olson, Brigid Hogan, Christopher Wright, and Rudi Balling for probes. The 129/Ola cosmid genomic library was obtained from the Resourcenzentrum (RZPD) in Berlin. The antineurofilament antibody $2 \mathrm{H} 3$ developed by Tom M. Jessell and Jane Dodd was obtained from the Developmental Studies Hybridoma Bank maintained by the University of Iowa. This work was supported by DFG grants to A.K. (DFG KI728/2) and A.G. (SFB271,B12).

The publication costs of this article were defrayed in part by payment of page charges. This article must therefore be hereby marked "advertisement" in accordance with 18 USC section 1734 solely to indicate this fact.

\section{References}

Aoyama, H. and Asamoto, K. 2000. The developmental fate of the rostral/caudal half of a somite for vertebra and rib formation: Experimental confirmation of the resegmentation theory using chick-quail chimeras. Mech. Dev. 99: 71-82.

Barrantes del Barco, I., Elia, A.J., Wünsch, K., Hrabe De Angelis, M., Mak, T.W., Rossant, R., Conlon, R.A., Gossler, A., and Pompa, J-L. 1999. Interaction between L-fringe and Notch signalling in the regulation of boundary formation and posterior identity in the presomitic mesoderm of the mouse. Curr. Biol. 9: 470-480.

Beckers, J., Caron, A., Hrabe de Angelis, M., Hans, S., CamposOrtega, J.A., and Gossler, A. 2000. Distinct regulatory elements direct Deltal expression in the nervous system and paraxial mesoderm of transgenic mice. Mech. Dev. 95: 2334.

Bettenhausen, B., de Angelis, M.H., Simon, D., Guénet, J.-L., and Gossler, A. 1995. Transient and restricted expression during mouse embryogenesis of D111, a murine gene closely related to Drosophila Delta. Development 121: 2407-2418.

Biben, C., Stanley, E., Fabri, L., Kotecha, S., Rhinn, M., Drinkwater, C., Lah, M., Wang, C.C., Nash, A., Hilton, D., et al. 1998. Murine cerberus homologue mCer-1: A candidate anterior patterning molecule. Dev. Biol. 194: 135-151.
Burgess, R., Cserjesi, P., Ligon, K.L., and Olson, E.N. 1995. Paraxis: A basic helix-loop-helix protein expressed in paraxial mesoderm and developing somites. Dev. Biol. 168: 296-306.

Candia, A.F., Hu, J., Crosby, J., Lalley, P.A., Noden, D., Nadeau, J.H., and Wright, C.V. 1992. Mox-1 and Mox-2 define a novel homeobox gene subfamily and are differentially expressed during early mesodermal patterning in mouse embryos. Development 116: 1123-1136.

Christ, B., Huang, R., and Wilting, J. 2000. The development of the avian vertebral column. Anat. Embryol. (Berl) 202: 179194.

Conlon, R.A., Reaume, A.G., and Rossant, J. 1995. Notch1 is required for the coordinate segmentation of somites. Development 121: 1533-1545.

Deutsch, U., Dressler, G.R., and Gruss, P. 1991. Pax1, a member of a paired box homologous murine gene family, is expressed in segmented structures during development. Cell 53: 617625.

De Vries, W.N., Binns, L.T., Fancher, K.S., Dean, J., Moore, R., Kemler, R., and Knowles, B.B. 2000. Expression of Cre recombinase in mouse oocytes: A means to study maternal effect genes. Genesis 26: 110-112.

Dunwoodie, S.L., Henrique, D., Harrison, S.M., and Beddington, R.S. 1997. Mouse Dll3: A novel divergent Delta gene which may complement the function of other Delta homologues during early pattern formation in the mouse embryo. Development 124: 3065-3076.

Dunwoodie, S.L., Clements, M., Sparrow, D.B., Sa, X., Conlon, R.A., and Beddington, R.S. 2002. Axial skeletal defects caused by mutation in the spondylocostal dysplasia/pudgy gene Dll3 are associated with disruption of the segmentation clock within the presomitic mesoderm. Development 129: 1795-1806.

Edmondson, D.G. and Olson, G.R. 1989. A gene with homology with the myc similarity region of MyoD1 is expressed during myogenesis and is sufficient to activate the muscle differentiation program. Genes \& Dev. 3: 628-640.

Goldstein, R.S. and Kalcheim, C. 1992. Determination of epithelial half-somites in skeletal morphogenesis. Development 116: 441-445.

Gossler, A. and Tam, P.P.L. 2002. Somitogenesis: Segmentation of the paraxial mesoderm and the delineation of tissue compartments. In Mouse development (eds. J. Rossant and P.P.L. Tam), pp. 127-149. Academic Press, San Diego, CA.

Goulding, M., Lumsden, A., and Paquette, A.J. 1994. Regulation of Pax-3 expression in the dermomyotome and its role in muscle development. Development 120: 957-971.

Horikawa, K., Radice, G., Takeichi, M., and Chisaka, O. 1999. Adhesive subdivisions intrinsic to the epithelial somites. Dev. Biol. 215: 182-189.

Hrabe de Angelis, M., McIntyre II, J., and Gossler, A. 1997. Maintenance of somite borders in mice requires the Delta homologue DII1. Nature 386: 717-721.

Huang, R., Zhi, Q., Brand-Saberi, B., and Christ, B. 2000. New experimental evidence for somite resegmentation. Anat. Embryol. (Berl) 202: 195-200.

Keynes, R.J. and Stern, C.D. 1984. Segmentation in the vertebrate nervous system. Nature 310: 786-789.

- 1988. Mechanisms of vertebrate segmentation. Development 103: 413-429.

Kraus, F., Haenig, B., and Kispert, A. 2001. Cloning and expression analysis of the mouse T-box gene Tbx18. Mech. Dev. 100: $83-86$.

Kusumi, K., Sun, E.S., Kerrebrock, A.W., Bronson, R.T., Chi, D.-C., Bulotsky, M.S., Spencer, J.B., Birren, B.W., Frankel, 
W.N., and Lander, E.S. 1998. The mouse pudgy mutation disrupts Delta homologue Dll3 and initiation of early somite boundaries. Nat. Genet. 19: 274-278.

Leitges, M., Neidhardt, L., Haenig, B., Herrmann, B.G., and Kispert, A. 2000. The paired homeobox gene Uncx4.1 specifies pedicles, transverse processes and proximal ribs of the vertebral column. Development 127: 2259-2267.

Lescher, B., Haenig, B., and Kispert, A. 1998. sFRP-2 is a target of the Wnt-4 signaling pathway in the developing metanephric kidney. Dev. Dyn. 213: 440-451.

Mallo, M. and Brändlin, I. 1997. Segmental identity can change independently in the hindbrain and rhombencephalic neural crest. Dev. Dyn. 210: 146-156.

Mansouri, A., Yokota, Y., Wehr, R., Copleland, N.G., Jenkins, N.A., and Gruss, P. 1997. Paired-related murine homeobox gene expressed in the developing sclerotome, kidney, and nervous system. Dev. Dyn. 210: 53-65.

Mansouri, A., Voss, A.K., Thomas, T., Yokota, Y., and Gruss, P. 2000. Uncx4.1 is required for the formation of the pedicles and proximal ribs and acts upstream of Pax9. Development 127: 2251-2258.

Neidhardt, L., Kispert, A., and Herrmann, B.G. 1997. A mouse gene of the paired-related homeobox class expressed in the caudal somite compartment and in the developing vertebral column, kidney and nervous system. Dev. Genes Evol. 207: 330-339.

Neubüser, A., Koseki, H., and Balling, R. 1995. Characterization and developmental expression of $P a x 9$, a paired-box-containing gene related to Pax1. Dev. Biol. 170: 701-716.

Nieto, M.A., Gilardi-Hebenstreit, P., Charnay, P., and Wilkinson, D.G. 1992. A receptor protein tyrosine kinase implicated in the segmental patterning of the hindbrain and mesoderm. Development 116: 1137-1150.

Pourquie, O. 2001. Vertebrate somitogenesis. Annu. Rev. Cell Dev. Biol. 17: 311-350.

Remak, R. 1850. Untersuchungen über die Entwicklung der Wirbelthiere. Erste Lieferung über die Entwicklung des Hünchens im Ei. Reimer, Berlin.

Rickmann, M., Fawcett, J.W., and Keynes, R.J. 1985. The migration of neural crest cells and the growth of motor axons through the rostral half of the chick somite. J. Embryol. Exp. Morphol. 90: 437-455.

Rida, P.C.G., Le Minh, N., and Jiang, Y.-J. 2004. A Notch feeling of somite segmentation and beyond. Dev. Biol. 265: 2-22.

Saga, Y. and Takeda, H. 2001. The making of the somite: Molecular events in vertebrate segmentation. Nat. Rev. Genet. 2: $835-845$

Saga, Y., Hata, N., Koseki, H., and Taketo, M.M. 1997. Mesp2: A novel mouse gene expressed in the presegmented mesoderm and essential for segmentation initiation. Genes \& Dev. 11: 1827-1839.

Stern, C.D. and Keynes, R.J. 1987. Interactions between somite cells: The formation and maintenance of segment boundaries in the chick embryo. Development 99: 261-272.

Swiatek, P. and Gridley, T. 1993. Perinatal lethality and defects in hindbrain development in mice homozygous for a targeted mutation of the zinc finger gene Krox20. Genes \& Dev. 7: 2071-2084.

Takahashi, Y., Koizumo, K., Takagi, A., Kitajima, S., Inoue, T., Koseki, H., and Saga, Y. 2000. Mesp2 initiates somite segmentation through the Notch signalling pathway. Nat. Genet. 25: 390-396.

Takahashi, Y., Inoue, T., Gossler, A., and Saga, Y. 2003. Feedback loops comprising D111, Dll3 and Mesp2, and differential involvement of Psen 1 are essential for rostrocaudal patterning of somites. Development 130: 4259-4268.
Verbout, A.J. 1985. The development of the vertebral column. Adv. Anat. Embryol. Cell Biol. 90: 1-122.

von Ebner, V. 1888. Urwirbel und Neugliederung der Wirbelsäule. Sitzungsber Akad. Wiss. Wien. III 97: 194-206.

Wang, H.U. and Anderson, D.J. 1997. Eph family transmembrane ligands can mediate repulsive guidance of trunk neural crest migration and motor axon growth. Neuron 18: 383 396.

Weinmaster, G., Roberts, V.J., and Lemke, G. 1992. Notch2: A second mammalian Notch gene. Development 116: $931-$ 941.

Williams, R., Lendahl, U., and Lardelli, M. 1995. Complementary and combinatorial patterns of Notch gene family expression during early mouse development. Mech. Dev. 53: 357368.

Wilkinson, D.G. 1992. Whole mount in situ hybridization of vertebrate embryos. In In situ hybridization: A practical approach (ed. D.G. Wilkinson), pp. 75-84. Oxford University Press, Oxford. 


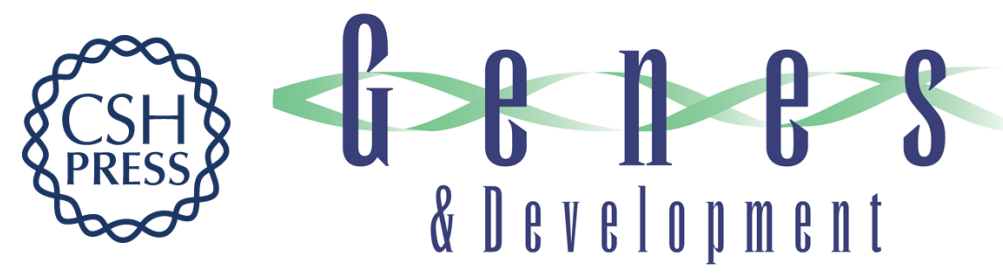

\section{The T-box transcription factor Tbx18 maintains the separation of anterior and posterior somite compartments}

Markus Bussen, Marianne Petry, Karin Schuster-Gossler, et al.

Genes Dev. 2004, 18:

Access the most recent version at doi:10.1101/gad.300104

Supplemental http://genesdev.cshlp.org/content/suppl/2004/04/27/18.10.1209.DC1
Material

References This article cites 45 articles, 16 of which can be accessed free at:

http://genesdev.cshlp.org/content/18/10/1209.full.html\#ref-list-1

License

Email Alerting

Receive free email alerts when new articles cite this article - sign up in the box at the top

Service

right corner of the article or click here.

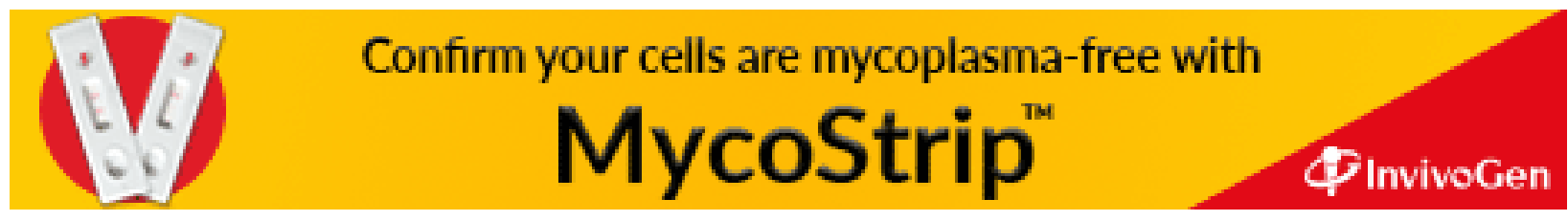

